\title{
Assessing the accuracy and dispersion of real estate investment forecasts
}

Article

Accepted Version

Papastamos, D., Stevenson, S. and Matysiak, G. (2015) Assessing the accuracy and dispersion of real estate investment forecasts. International Review of Financial Analysis, 42. pp. 141-152. ISSN 1057-5219 doi: https://doi.org/10.1016/j.irfa.2015.01.014 Available at https://centaur.reading.ac.uk/40906/

It is advisable to refer to the publisher's version if you intend to cite from the work. See Guidance on citing.

To link to this article DOI: http://dx.doi.org/10.1016/j.irfa.2015.01.014

Publisher: Elsevier

All outputs in CentAUR are protected by Intellectual Property Rights law, including copyright law. Copyright and IPR is retained by the creators or other copyright holders. Terms and conditions for use of this material are defined in the End User Agreement.

\section{www.reading.ac.uk/centaur}

\section{CentAUR}

Central Archive at the University of Reading 
Reading's research outputs online 


\section{Henley \\ Business School}

UNIVERSITY OF READING

\section{Assessing the Accuracy and Dispersion of Real Estate Investment Forecasts}

Accepted for publication in International Review of Financial analysis

Dimitrios Papastamos (Eurobank), Simon Stevenson (University of Reading) \& George Matysiak (Krakow University of Economics) 


\section{Assessing the Accuracy and Dispersion of Real Estate Investment Forecasts*}

Dimitrios Papastamos ${ }^{\dagger}$, George Matysiak ${ }^{\ddagger} \&$ Simon Stevenson ${ }^{\S}$

\footnotetext{
* The authors would like to extend their thanks to the Investment Property Forum (IPF) for their support of this research and for the provision of the forecast data.

${ }^{\dagger}$ Eurobank EFG Property Services S.A.

Master Management Group and Krakow University of Economics

$\S$ Author to whom correspondence should be addressed. School of Real Estate \& Planning, Henley Business School, University of Reading, Whiteknights, Reading, Berkshire, RG6 6UD, UK. Tel: +44118-378-4008. (s.a.stevenson@ reading.ac.uk)
} 


\title{
Assessing the Accuracy and Dispersion of Real Estate Investment Forecasts
}

\begin{abstract}
Existing empirical evidence has frequently observed that professional forecasters are conservative and display herding behaviour. Whilst a large number of papers have considered equities as well as macroeconomic series, few have considered the accuracy of forecasts in alternative asset classes such as real estate. We consider the accuracy of forecasts for the UK commercial real estate market over the period 1999-2011. The results illustrate that forecasters display a tendency to under-estimate growth rates during strong market conditions and over-estimate when the market is performing poorly. This conservatism not only results in smoothed estimates but also implies that forecasters display herding behaviour. There is also a marked difference in the relative accuracy of capital and total returns versus rental figures. Whilst rental growth forecasts are relatively accurate, considerable inaccuracy is observed with respect to capital value and total returns.
\end{abstract}




\section{Assessing the Accuracy and Dispersion of Real Estate Investment Forecasts}

\section{1: Introduction}

Over the course of the last two decades real estate has become a more mainstream asset class and in turn sophistication in the investment process has increased. In today's environment the majority of major investors utilise forecasts in some form in their asset allocation decision making. Not only do many institutions have their own in-house forecasters, but a large number of advisory firms and dedicated research organizations add to this intellectual capital and expertise within the real estate industry. The increased use, and importance, of forecasts has been mirrored by the expansion of quantitative modelling research in the academic literature. However, despite the increased awareness of the potential role of forecasting, in both a professional and academic context, very few papers have examined the accuracy of professional forecasts in real estate.

This lack of empirical examination is in contrast to the large literature concerned with the accuracy and characteristics of forecasts in the equity markets ${ }^{1}$. However, real estate provides an interesting and quite different context in which to consider the accuracy of forecasts. The nature of both its pricing and trading as a privately traded asset is in marked contrast to the equity markets. Specifically, as both a real and investment asset, real estate combines elements from the macroeconomy and the capital markets. In many respects, real estate has more behavioural characteristics in common with macro-economic series than equities. In particular, real estate data has long been recognized to display smoothing (e.g. Geltner, 1991, 1993) which contributes to reduced volatility in comparison with exchange traded assets such as stocks. The nature of the forecasting process also differs with emphasis on overall market conditions and trends in contrast to estimates of individual company. Therefore, in many respects a greater parallel exists with the literature to have considered the accuracy of macro-economic forecasting rather than the literature concerning stocks ${ }^{2}$.

The analysis in this paper is based upon both consensus and individual forecasts collected by the Investment Property Forum (IPF), a UK based industry body. The results highlight that forecasters 
tend to display conservatism in their published forecasts, with the result that they under-estimated the growth rates observed during the strong market conditions up to 2007, and under-estimated the extent of the subsequent fall in values. These findings may be possibly linked to herding and a reluctance to provide extreme forecasts. It also noticeable that greater accuracy is observed in the case of the rental (income) return forecasts in comparison to those for capital and total returns. This is possibly due to difficulty in accurately gauging and incorporating factors such as investment behaviour and flow of funds and their consequent impact on yields and capital values. This impact is shown by the low frequency in which the IPF Consensus Forecasts for capital and total returns outperform simple naive forecasts. In addition, when the underlying individual forecasts are considered, the forecast ranges are much larger than with the corresponding rental growth figures.

The paper is structured as follows. Section 2 discusses some of the pertinent issues in both the broad forecasting literature as well as those limited number of papers to have specifically considered real estate. Section 3 describes the data analysed in the paper. The empirical analysis is broken into two primary components. The first provides an initial examination of the accuracy of both the IPF Consensus as well as the dispersion and variation of the individual forecasts. The second element compares the performance of the consensus versus simple naive forecasts. Section 6 discusses in more depth some of the broader implications that arise from the empirical findings, and in particular possible causes behind the heightened inaccuracy displayed with respect to capital and total return forecasts. The final section provides concluding comments.

\section{2: Literature Review}

The macroeconomic forecasting literature has highlighted a variety of factors that may contribute to, and explain, variations in forecast accuracy. There will inevitably be variations across empirical approaches and model choice; however, Oller \& Barot (2000), Hendry \& Clements (2003) and Stekler (2007) note several possible reasons as to why models may fail to provide accurate forecasts, including model mis-specification and issues such as the use of inaccurate data. In addition, the presence of structural breaks may affect the deterministic trend. For example, both Stock \& 
Watson (1993) and Fintzen \& Stekler (1999) note that series that had previously managed to capture anticipated economic downturns failed to do so for the 1990 recession in the United States.

The characteristics and the behaviour of individual forecasters is a further key element that may affect forecasting performance and is subject to a large number of empirical papers. Gjaltema (2001) argues that forecasters are distinctive entities with individual characteristics that can influence forecast outcomes. Furthermore, Fintzen \& Stekler (1999) argue that the manner in which individuals prepare their forecasts can affect their accuracy. Gallimore \& McAllister (2005) pinpoint five key areas where judgemental, or behavioural elements may come into play in the forecasting process. These are i) during model formation, ii) during model evaluation, iii) in the evaluation of provisional forecasts, iv) in the production of pure judgemental forecasts and v) by users implementing the forecasts ${ }^{3}$. One key behavioural element is that forecasters may deliberately bias their forecasts. There are a number of studies that have argued that forecasters may not necessarily attempt to maximize forecast accuracy and may be motivated by factors such as their reputation when they release forecasts ${ }^{4}$. A recent paper by Tillman (2011) shows how forecasts produced by members of the Federal Open Market Committee (FOMC) of the Federal Reserve may bias their own individual forecasts for policy reasons. Whilst Hong \& Kubik (2003) consider equity analysts forecasts, their findings are consistent with the above. They argue that the prospects of promotion inside a firm guide analysts towards optimistic forecasts. A factor that possibly contributes to this is that optimistic forecasts may help generate trading activity. Dechow et al. (2000) provides supporting evidence in the context of forecasts from banks. The results illustrate that forecasts tend to be more optimistic when concerned with firms with whom the bank has a business relationship in comparison to forecasts produced by 'de-motivated' forecasters.

Laster et al. (1999) note that the publicity that occurs on the release of a forecast may affect the outcome, leading possibly to deliberately biased forecasts. Gallimore \& McAllister (2005) provide qualitative evidence, based on structured interviews, to support such behaviour occurring in a real estate context. Some participants expressed a reluctance to provide downbeat negative forecasts due to the anticipated response of end-users. Such findings are supportive of the incentive concavity 
theory which would suggest that the rewards from making an accurate but bold forecast are smaller than the penalties of an inaccurate bold forecast (Batchelor, 2007). This often therefore leads to herding and a clustering of forecasts around the consensus ${ }^{5}$. The rationale behind forecasters herding around the consensus may also vary depending on market conditions. Inaccurate forecasts possibly avoid undue attention when conditions are strong as market participants may be concentrating on the good news of 'better than expected results'. In poor investment market conditions, worse than forecast figures may be blamed upon 'the market'. These behavioural characteristic may lead to forecasters under-estimating growth rates when the market out-performs and vice-versa (Zarnowitz \& Braun, 1993).

The resulting smoothing that may occur in forecasts also arises due to the statistical properties of optimal forecasts which state that the variance of the forecasts must be less than the variance of the actual values (Mincer \& Zarnowitz, 1969; Samuelson, 1976). However, Smyth \& Ash (1981) show that this relationship (i.e. greater variance in the actual values than in forecasts) exists for the longer forecasting horizons and not for the shorter ones. This is because for shorter horizons, forecasters knowing the actual data, use their judgment to adjust estimates appropriately. Thus, as forecasts are a dynamic procedure, forecasters have to use their judgment during the entire process. However, such an effect does not necessarily mean that the dispersion or variation of forecasts follows the same pattern, Papers such as Lahiri \& Sheng (2008) and Patton \& Timmermann (2010) illustrate how dispersion is greater at longer forecast horizons. More generally, both McNees (1990) and Donihue (1993) highlight the importance of judgmental adjustments on the predictive accuracy of econometric models. Lahiri \& Sheng (2010) show how individual judgment can determine forecast uncertainty and in turn forecast accuracy.

There is also evidence that forecasters try to avoid large adjustments in their released forecasts (Scotese, 1994). Batchelor \& Dua (1991) observe that forecasters not only display conservatism in order to be closer to the consensus but that, more generally, they revise their estimates by less than warranted by new information. Instead, they prefer to wait until later revisions of data are available before adjusting their models. The findings of Isiklar et al. (2006) support this, 
reporting that it takes forecasters more than five months to incorporate $90 \%$ of new information. Batchelor (2007) notes three possible reasons as to why forecasters may publish persistently biased forecasts. One is a lack of appropriate skills and the inability to efficiently incorporate new information. Forecasters may also fail to learn from past forecast errors and as a result they produce biased forecasts on an ongoing basis. The second reason is that forecasters may fail to differentiate between the changes in the target variable that are permanent and those which are transitory. Effectively, they may assign an equal weight to each component, resulting in biased forecasts. The third possible reason, as has already been noted, is the financial or reputational incentives that may lead to overly optimistic or pessimistic forecasts.

In a real estate specific context very few papers have considered the issue of forecast accuracy. Ling (2005) analyses forecasts for the US market provided by the Real Estate Research Corporation (RERC). The results indicate that the consensus opinions analysed are backward looking and reveal little information in terms of subsequent performance. McAllister et al. (2008) analyse the same IPF forecast data used in the current study. The main constraint facing McAllister et al. (2008) is that they only analyse data from 1999 through 2004. Not only does this sample miss the market correction observed in 2007 and 2008 but also the strong positive returns seen in 2005 and 2006. However, despite those limitations the results do reveal a number of interesting elements, specifically evidence that herding is a common characteristic among forecasters. Bond \& Mitchell (2011) also consider the IPF data, although in a different context. Their analysis compares the forecasting accuracy of the IPF Consensus Forecast for total returns versus implied forecasts derived from total return swap contracts. The results, interestingly, show that for a one-year horizon, the derivatives based implied forecasts display greater accuracy than the published consensus forecast.

\section{3: Data}

Since the late 1990's the IPF has surveyed a variety of property advisory firms, fund managers and financial institutions and asked them to provide forecasts of rental growth, capital value 
growth and total returns for the UK commercial real estate market ${ }^{6}$. Our analysis is able to expand upon that contained in previous work in a number of respects. Most importantly, we are able to consider not only the accuracy of the IPF Consensus Forecasts but also individual forecasters. Secondly, by expanding the sample period through to 2011 we are able to consider whether accuracy varies over the course of a cycle. Finally, we also look at two-year forecasts as well as the one-year estimates.

The benchmark reference point specified is the return for the relevant annual index produced by Investment Property Databank (IPD), the primary index provider for the UK commercial real estate sector. The IPD indices are value-weighted and cover all of the major investment property types. Due to the small number of transactions in the commercial property market the indices are based upon valuation data for individual properties ${ }^{7}$. This data is provided to IPD by institutional investors, therefore the composition of the indices reflects the investment preferences of the participating institutions. In accordance with practice in the UK the appraisals are independently provided by one of the property service firms in accordance with the valuation standards of the Royal Institution of Chartered Surveyors (RICS). Table 1 details the composition of the index at the end of 2011. It can be seen that the index is dominated by the larger property sectors and markets, such as Shopping Centres and Central London Offices. The retail sector comprises just over half of the IPD index, with the vast majority of the remainder being made up of office and industrial properties. This breakdown reflects both the investment preferences of the institutions who supply IPD with data and the effect of value-weighting. The impact of these factors can also be observed in the geographic concentration of the index in London and the South East of England.

The IPF Consensus for each of the three series is based upon the simple average (mean) figure obtained from the individual forecasts. The overall dataset includes 69 forecasters, comprising 22 property advisors, 26 fund managers and 21 brokers. However, continuous data for all 69 firms is not available for each and every single period and for each of the forecast variables, therefore, our sample does vary in size from period-to-period. For example, for the one-year ahead forecast of rental values, the number of forecasts in any individual year ranges from 18 to $29^{8}$. 


\section{4: Empirical Results I: The Accuracy of the Consensus and the Dispersion of Individual Forecasters}

The first component of the empirical analysis considers the accuracy of the IPF Consensus as well as a preliminary examination of the divergence and variation in the individual forecasts. Table 2 provides details on the consensus forecasts produced together with the actual outcomes for the three series considered for the one and two year forecast horizons. Figure 1 graphically depicts this information. Table 2 also includes the minimum and maximum individual forecast for each year as well as the range, mean forecast error, skewness and Jacque-Bera statistic for normality.

A number of issues are apparent from this initial examination of the data. Firstly, it is clear that the consensus tends to overestimate the three series in underperforming periods of the property market and vice versa. Throughout the strong conditions present between 2004-7 forecaster's consistently under-estimated market performance. In contrast, the extent of the market decline surrounding the 2007-8 financial crisis was substantially under-estimated. This finding is consistent with the broad macro-economic forecasting literature (e.g. Zarnowitz \& Braun, 1993). We can also see that forecasters have a tendency to be conservative in in their forecasts and avoid 'big numbers'. In the broader forecasting literature, Scotese (1994) argues that forecasters seek to avoid sudden and large adjustments in order to try and maintain their reputation and credibility. The result of such behaviour is forecast smoothing. This impact can also be observed when one considers the variation of the consensus in comparison to the observed outcomes. Table 2 reports standard deviations for both the forecasted and actual outcomes and in each and every case the variability of the actual series is greater than the forecasts. This effect is more prominent in the two year horizons, consistent with papers such as Smyth \& Ash (1981). Furthermore, the volatility of the two year ahead forecasts is lower in each case when compared to the respective one year estimate. This does suggest increased conservatism over longer horizons. This may be possibly due to forecasters reverting back to the longrun average. It does however, need to be noted that a further possible factor behind the reduced variability is an averaging effect. An element of smoothing may be introduced into the consensus forecast due to it being estimated as the simple average of the individual forecasts. 
In order to assess more fully assess the forecasts we use three standard measures of accuracy, namely; Mean Absolute Error (MAE), Mean Squared Error (MSE) and the Root Mean Squared Error (RMSE). All of these measures are commonly used in the economic forecasting accuracy literature (e.g. Makridakis et. al., 1998; Clements et al., 2007; Lahiri \& Sheng, 2010; Lenten, 2012). The three measures are defined as below, and in each case the smaller the value the higher the degree of accuracy.

$$
\begin{aligned}
& \mathrm{MAE}=\sum_{i=1}^{n} \frac{|e|}{n} \\
& \mathrm{MSE}=\sum_{i=1}^{n} \frac{e^{2}}{n} \\
& \mathrm{RMSE}=\sqrt{\sum_{i=1}^{n} \frac{e^{2}}{n}}
\end{aligned}
$$

Where $e$ is the forecast error (i.e. the difference between the actual and the forecast value) and $n$ is the number of the forecasters. The MAE measure therefore avoids offsetting effects from large positive and negative errors. The Mean Square Error overcomes the same issue by squaring the forecast error rather than take the absolute error. In addition, by taking the square of the forecast error the measure is effectively penalizing more heavily forecasts with large errors. The Root Mean Squared Error is simply the square root of the MSE, thereby returning it to the same unit of measurement. These statistics are displayed in Table 3.

It can be seen that the largest errors in the case of the capital and total returns are forecasts of 2008. Both the one-year forecasts produced in 2007, and two-year estimates, from 2006, report the highest degree of errors for any period. The fact that this is consistent not only across the three measures but for both the one and two year horizons illustrates the degree to which capital values, and thus total returns, fell in 2008. It is interesting that the largest errors in the case of rental forecasts were observed later, 2010 for one-year forecasts and 2009 in the two-year case. These findings are 
confirmed if one also looks at the data in Table 2, where it is clear that the largest deviation from the actual outcome with respect to capital and total returns is observed when forecasting 2008. The Consensus Forecast for capital growth in 2008 , as forecasted in 2007, was $-3.78 \%$. The reality was a decline in capital values by $26.32 \%$. A similar divergence is also noted with total returns. Whilst the Consensus Forecast for 2008 was $1.15 \%$, total returns were actually negative to the tune of $-22.10 \%$. It does need to be noted at this point that the one-year ahead forecasts were made after the financial crisis had gathered momentum in the late summer of 2007. Furthermore, the UK commercial property market saw substantial declines in the last quarter of 2007. Therefore, the inaccuracy observed is not simply due to a timing issue. Whilst this may be viewed as mitigating evidence with respect to the two-year ahead forecasts for 2008, as they were produced in 2006, it does not stand up as an argument with respect to the one-year ahead forecasts.

If one compares the one and two year ahead forecasts for 2008 it can be seen that whilst forecasters took a more bearish view in 2007 in comparison to 2006 the change in sentiment was relatively minor. For example, expected capital value growth in 2008 was forecasted in 2006 as being $-0.15 \%$. This was revised to $-3.78 \%$ in 2007 . Similarly minor revisions were made with respect to both rental growth and total returns. In addition, following the substantial fall in capital values and total returns in 2008 , forecasters continued to forecast a downward trend for 2009 , missing the turning point in that year. Clearly, the experience of 2008 had an influential impact on the forecast for the following year. For the rental growth the largest consensus one-year ahead forecast deviation is observed for the target year 2010. The Consensus Forecast was $-6.10 \%$, whereas the actual value recorded was $-0.50 \%$. As with the capital values and total returns in the preceding year, the poor performance of the rental market in $2009(-7.90 \%)$ may have contributed to overly pessimistic forecasts being delivered for 2010 .

Another feature of the results that is clearly evident is that the forecasts tend to display greater accuracy when the rental series is considered. This is the case for both horizons and in both phases of the last cycle and is noticeable in the findings in Table 2 as well as the more formal accuracy measures in Table 3. Forecasts were considerably under-estimated during the 2004-6 period and over- 
estimated in the subsequent crash. For example, the one-year capital value consensus figures for 2004 through 2006 were $0 \%, 2.4 \%$ and $2.8 \%$. In reality the benchmark IPD Capital Value index rose by $11.4 \%, 12.8 \%$ and $12.6 \%$ in those three years. A possible factor in this respect is that forecasters do not appear to fully capture then enhanced variability present in the capital and total return series'. If one looks at both the actual and forecast series it is apparent that the volatility of the capital and total return series are substantively higher than is the case with the rental growth data. If one considers the full 2000-2011 sample the standard deviation of the actual series for capital and total returns is in excess of $10 \%$. In contrast the variability of the rental index is $3.99 \%$. However, if one then compares the standard deviations of the respective forecast series then there is not a noticeable difference between the three series. In the case of the one-year ahead forecasts, the standard deviation of the rental forecasts is $3.55 \%$ whilst the corresponding figures for the capital and total return data are $4.38 \%$ and $4.66 \%$. Although higher, in neither case do the respective figures approach the actual volatility of the series being forecasted.

Table 2 also reports skewness and normality statistics. These are of interest as they can be interpreted in terms of overly optimistic or pessimistic forecasts. For example, in 2006 all three oneyear forecasts report not only significant Jaque-Bera statistics but in addition displayed negative skewness. This can be taken as implying overly pessimistic forecasts. If one considers the simple Mean Forecast Errors (MFEs) for 2006 this interpretation is confirmed. In all three cases for rental growth, capital value growth and total returns MFEs are respectively reported of 1.61, 9.80, 9.42. Linden (2003) argues that significant skewness in the distribution of forecasts can be a signal of upside and downside risk, dependent on market conditions.

To complement the findings shown in Table's 2 and 3and Figure 1we construct Box-Whisker plots, displaying the mean and median of the forecasts for each period together with minimum and maximum. The box surrounding the mean denotes the interquartile range. The plots displayed in Figures 2 and 3 summarise the distribution of the individual forecasts made one and two years prior to the indicated year. As already seen in the context of the consensus, rental forecasts tend to more closely track actual outcomes than is the case with capital value growth and total returns. This is 
especially evident during the 2004 to 2006 period. To some extent this is not particularly surprising given the strength in capital value appreciation during this period, and that it was predominantly driven by a strong downward movement in yields. Whilst it is acknowledged that forecasting the impact of yields on capital values is difficult due to the nature of investment flows, the heightened sensitivity of capital values to yields in periods of low yields makes the task of accurately forecasting them even more challenging. However, there are distinct patterns in the forecasts. In the 2004 to 2006 period capital values rose by more than the highest individual forecast provided. This is true for both one and two year ahead forecasts. In addition, significant negative skewness, as well as positive mean forecast errors is observed in 2005 and 2006. In contrast, as capital values fell during the subsequent market reversal, then fell by more than the most pessimistic forecaster anticipated for both 2007 and 2008. Therefore, it would appear that some behavioural aspects do come to the fore in that forecasts tended to provide more conservative forecasts in the case of capital, and therefore total returns, during the extremes of the last cycle.

The results provide evidence that dispersion in the forecasts widened during the post 2007 period, implying greater uncertainty in the market place. For all three data series and for both forecasting horizons the variability across forecasts increased in the post 2007 period. As can be seen in both Table 4 and the Box-Whisker charts, in 5 out of 12 years annual rental growth was outside the one-year forecast range. Furthermore, for the one year forecasts it is observed that in eight out of twelve years the annual capital growth and total return was outside the respective forecast range. In effect, forecasters failed to predict the trend in capital values in eight out of twelve target years. Particularly, for 2007 and 2008 capital and total returns were substantially overestimated. Forecasters do tend to capture more accurately the trend in rents. This can be seen clearly in the smaller forecast ranges, implying reduced forecasting disagreement.

The greater forecasting accuracy with respect to rental growth can also be observed by considering the simple correlations of the actual values with the Consensus Forecasts. Table 4 reports the correlation coefficients between the consensus and actual figures. A statistically significant positive correlation $(+0.74)$ between the one-year ahead forecast of rental growth and the observed 
results is found. In contrast, there is no significant correlation reported with respect to either capital or total returns, with the corresponding coefficients being 0.42 and 0.50 respectively. Furthermore, at no time do we see significant correlations in the case of the two-year ahead forecasts. However, it should be noted that in addition to the significant contemporaneous correlation observed in the case of the one-year rental growth forecasts, there is also evidence of a lagging effect, as seen in Figure 1. It would appear that forecasters place a great degree of attention on the current year's performance when making subsequent forecasts. The correlation between rental forecasts and the actual performance of the rental index rises to 0.85 when lagged.

\section{5: Empirical Results II: The Comparative Performance versus Naive Forecasts}

As noted earlier in the paper, the Bond \& Mitchell (2011) comparison between the IPF Consensus and forecasts implied from swap contract quotes saw the derivative based forecasts outperform over short-term one-year horizons. We expand upon this analysis to compare the performance of the consensus against two alternative naive forecasts. The first (Naive 1) assumes no change in the previous year's value, at the time the forecast was made. The second naive forecast (Naive 2) is based on the long-term average of the respective IPD index return, up to the point at which the forecast was made. For example, for forecasts made in 2002, the long-term average growth rates of the appropriate IPD index up to 2002 are used. This approach avoids potential bias through the incorporation of subsequent data into the naive forecast ${ }^{9}$. To compare the performance versus the alternative naive measures we use Theil's U2 statistic (Theil, 1966, 1971), which can be represented as follows:

$$
\text { Theil's U2 }=\sqrt{\frac{\sum_{t=1}^{n-1}\left(\frac{F_{t+1}-Y_{t+1}}{Y_{t}}\right)^{2}}{\sum_{t=1}^{n-1}\left(\frac{Y_{t+1}-Y_{t}}{Y_{t}}\right)^{2}}}
$$


where $F$ is the forecast and $Y$ is the actual observation. Theil's U2 statistic can therefore be interpreted as dividing the Root Mean Square Error (RMSE) of the given forecast by the RMSE of a naive forecast. The statistic therefore provides the basis for comparing alternative forecasts relative to a naive forecast. If it has a value less than 1 the Consensus Forecast is better than those obtained by employing a naive forecast. If it has a value equal to 1 , the forecasts add nothing, as the naive would be just as effective. If the value is greater than 1 the naive can be interpreted as having out-performed the Consensus.

The results are displayed in Tables 5 and 6. Table 5 reports the Theil U2 statistics, whilst Table 6 provides a summary of the number of years in which the two naive forecasts outperformed the consensus. With respect to the rental growth series on five out of twelve occasions Naive 1 (the previous year's outcome) results in a lower error. In the case of Naive 2 (the long-term average up to the year of forecast) it outperformed on six of the twelve occasions. As for the two year ahead forecast period, in only two of the eleven years did Naive 1 outperform the consensus, whereas Naive 2 outperformed on four occasions. Therefore, the Consensus rental forecasts do outperform in the majority of years, a result that does provide some support in terms of the value of forecasts. However, as just noted, there is evidence that the one-year rent forecasts do have a strong relationship with the actual growth rates at the time of the forecast.

These findings are not however, repeated with the capital or total return data. The results support the preceding analysis in observing reduced accuracy with respect to capital and total return forecasts. When looking at the one-year ahead forecasts Naive 1 outperforms the consensus on seven and six occasions for capital and total returns respectively. In the case of Naive 2 this number increases to ten for both series. Similar levels of underperformance are also noted with respect to the two-year ahead forecasts, especially in the case of Naive 2, with it outperforming the consensus in eight out of eleven periods. It is of interest that most of the periods in which the consensus outperformed were towards the end of the sample. Intuitively the reverse may be expected given the extreme market movements observed between 2007 and 2009. However, in most cases, especially with the capital and total returns, the periods of under-performance were concentrated in the pre-2007 
period. For example, the one year consensus capital return forecast under-performed Naive 1 in every year from 2001 to 2006, as well as 2008. In the case of Naive 2 the consensus only outperformed in 2007 and 2008.

There is also generally an improvement in the relative performance of the consensus forecasts in the case of the two year horizons. It may be that for the two year horizons (conditional) information on the outlook for the market is more accurately captured. These results also provide support to the results reported in Bond \& Mitchell (2011). Whereas they illustrated that the published consensus underperformed derivative based forecasts of total returns over short horizons, our findings show that even simple naive forecasts can display heightened accuracy.

\section{6: Performance of Capital and Total Return Forecasts}

A key finding in the empirical results is the disparity between the relative accuracy of rental growth forecasts in contrast to those of capital and total returns. This is not only evident in the reported accuracy of the Consensus Forecast but also that over a number of forecasting horizons the range of forecasts did not encompass the actual resulting growth rate. This was the case not only in 2007 and 2008 when we observed extreme negative returns in capital and total returns, but also during the boom years of 2003 through 2006. In each of these years not only did the Consensus underestimate capital value returns but so did each individual forecaster. The same observation can be made for total returns. Furthermore, the number of periods in which the Consensus forecasts for capital and total returns outperformed the alternative naive forecasts is far lower than is the case with the rental forecasts.

There are a number of issues potentially contributing to this heightened inaccuracy. Firstly, forecasts of capital and total returns incorporate a number of factors above and beyond those impacting upon the underlying occupational property market. In particular, capital values are influenced not only be rental values but also by yields. Yields in turn are influenced by factors such as 
interest rates, perceived risk premiums, investment behaviour and flow of funds. It is possible that the marked difference in relative accuracy in part reflects the difficulty in forecasting these factors and their corresponding impact upon capital values. In addition, it may also simply imply enhanced awareness and expertise in producing forecasts of underlying occupational property market fundamentals ${ }^{10}$.

However, the changing nature of the underlying market during the last cycle also needs to be brought into consideration. Specifically, over the last decade capital values have been predominantly yield, and therefore investor, driven. Figure 4 displays the annual growth rates for the IPD annual indices, the reference points set by the IPF, from 1971 to 2010. The growth rates are for capital and rental values. In addition, the IPD Yield Impact series is presented. This series denotes the change in capital values that would be implied by a change in yield. Therefore, by comparing the three series it is possible to consider the driving forces of capital values. It is clear for much of the seventies, eighties and nineties the change in capital values was being driven by changes in income, denoted by the rental series. There are a couple of exceptions, namely 1974 and 1993, when yield changes were the primary factor in capital value returns. However, these can be attributed to interest rate shocks, namely the oil crisis of the mid-seventies and the ERM (Exchange Rate Mechanism) crisis of 1992$93^{11}$. However, with the exception of these two periods, in the majority of years changes in capital values broadly follow rental values. From 1970 to 2001 the correlation between the capital and rental growth series is 0.62 , rising to 0.84 if the two outlier years of 1974 and 1993 are excluded. In contrast the last decade has seen capital values predominantly driven by yield changes, indicative of an investor driven market ${ }^{12}$. The correlation between the rental and capital growth series fell to -0.15 in the 2002 to 2010 period. In contrast, the corresponding correlation with the yield impact series was 0.98 in the same period.

Part of the reason behind this shift to a yield driven market is the downward movement in yields observed in the UK from 2002 to 2007. This period of 'yield compression' saw the monthly IPD all property initial yield reach a low of $4.57 \%$ in both December 2006 and in the summer of 2007, declining from a figure in excess of $7 \%$ in $2002^{13}$. In contrast, rental growth during this period was 
generally quite sluggish, as Figures 2, 3 and 4 all illustrate. Furthermore, if one considers the monthly IPD series it can be seen that whereas capital values increased by $48.96 \%$ from December 2002 to August 2007, the corresponding increase in the all property rental value index was only $9.32 \%$. The dominance of yield movements is not however, solely due to the simple effect of falling yields at a time of moderate rental growth. A further factor is the non-linearity in the yield-to-present value relationship, meaning that at lower yields capital values are more sensitive and thus move more in percentage terms. The yield compression observed in the market therefore had the result of property capital values being estimated at extremely low historical yields, resulting in heightened sensitivity and therefore very large capital value movements. This explains why in both the strong upward market conditions of 2004-7 and during the market correction of 2007/8, capital values movements were not only so large but why they also were the primary driving force in total returns. The key issue in the context of our analysis is whether this non-linearity was fully accounted for in the capital value growth forecasts. A result reported in Table 2, and commented upon earlier in the paper warrants further mention. It was previously noted how the volatility of the forecasts of capital and total returns were not only far below the corresponding volatility of the actual index returns, but that they were more similar to those observed with respect to rental value growth. As we previously reported, the standard deviation of the actual annual capital and total return series is in excess of $10 \%$, whereas the volatility of the corresponding forecast series were $4.38 \%$ and $4.66 \%$ respectively. This would provide some modicum of support to the notion that the forecasts did not capture the changing dynamics of capital and total returns in the sense that the volatility of the series rose substantially during the post 2002 period.

This issue is also related to other possible factors influencing forecast inaccuracy in capital value forecasts. As both Gallimore \& McAllister (2005) and Bond \& Mitchell (2010) note, it is often the case that such forecasts are not actually directly estimated, rather they are implied from forecasts of yields. However, if this is the case and forecasts of capital and total returns are being, at least part, derived from estimates of yields, then during periods of very low yields inaccuracies in such forecasts will be magnified when converted to imply capital value growth. This is due to a two-fold impact 
resulting from the non-linearity of the present value-yield relationship. Figure 5 illustrate this with a simple example. Figure 5 displays the initial yield series for the Annual IPD All Property Index together with the change in capital values implied by these yield changes based on a simple perpetuity valuation assumption. Figure 5 also reflects the 'forecasted' change in capital value based on an under-estimated movement in yield. This simple scenario is based upon a forecaster correctly gauging the direction of yields, however, they under-estimate the movement by half. For example, in 2004 the actual initial yield was $5.8687 \%$, falling to $5.1604 \%$ a year later. We assume that the forecaster underestimated this downward shift by half, thus forecasting a yield of $5.5145 \%$. A similar assumption is made in each year, with the implied capital growth based on these forecasted yields reported in Figure 5. It can be seen that the implications for the capital value forecasters is significant. For example, based on in initial yields capital values rose by $13.7258 \%$ in 2005 . In comparison, our estimated yield implied capital appreciation of only $6.4222 \%$. The non-linearity of the present value relationship means that the capital value growth estimates are highly sensitive to possible errors in the yield forecasts and also lead to a magnification in the forecast error. It can be seen that for each year between 2003 and 2007 the forecast change in capital values was less than $50 \%$ of that based on actual changes in initial yield. This is despite the 'yield forecast' under-estimating movement by $50 \%$ in each year. Therefore, the forecast error was magnified and enhanced when capital growth was implied from yield forecasts.

As previously noted Batchelor (2007) presents three possible causes behind persistent bias, namely; a failure to efficiently incorporate new information; a failure to differentiate between permanent and transitory changes and finally behavioural elements such as financial or reputational incentives. Certainly behavioural elements may help to explain the lack of extreme forecasts and the presence of herding and conservatism in the forecasts. However, the first two of Batchelor's (2007) points are also of interest in the context of the capital and total return forecasts. Given the change in market dynamics it is possible that forecasts did not fully capture the shift towards a yield driven market, nor fully take into account the impact of the non-linearity at such low yields. It may be that either existing econometric models failed to either capture the degree of yield compression or that 
yield movements were dominating changes in capital value. In addition, it may be that forecasters failed to realise that the changes observed were not transitory.

In addition, as both Gallimore \& McAllister (2005) and Bond \& Mitchell (2010) note, formal econometric modelling is less common in the context of yields. Rather judgemental forecasts and overlay opinions are used to a greater extent with yields. Therefore, it may be that overlay opinions contributed to an under-statement of yield movements. One possible cause in this respect is the nature of traditional institutional investment. Institutional investors still largely adopt a more risk-averse investment strategy, one that involves low, if any, gearing, longer holding periods and a greater emphasis on income for their return. At the height of the market the low yield levels meant that many traditional institutions were facing conditions not conducive to their investment strategies. Rather, the low level of yields suited more aggressive investors who were focusing more upon capital appreciation over shorter holding periods. Effectively such investors could take advantage of the nonlinearity in the present value relationship. Furthermore, aided by the relatively easy availability of capital, such investors could further enhance their return by using high levels of gearing. It may therefore be that internal viewpoints, driven by the relative lack of viable investment opportunities for traditional property institutions influenced the forecasts.

\section{7: Concluding Comments}

This paper has considered the accuracy of forecasts of the UK real estate market. Based upon both the IPF Consensus Forecasts and the individual forecasts underpinning this figure, we find that forecasters tend to display conservatism. This results in under-estimation of return figures in both boom and crash conditions. This is consistent with, and provides quantitative support for, the qualitative interview findings reported in Gallimore \& McAllister (2005). There is also evidence of herding behaviour. It is of interest that the accuracy of the rental growth forecasts is substantially better than that reported with respect to capital and total returns. Based upon the Theil's U2 statistics, consensus forecasts of capital growth and total returns are no better and, indeed, worse on some 75 
per cent of occasions than a naive forecasting rule. Furthermore, when the underlying individual forecasts are considered, the forecast ranges are much larger than with the rental growth forecasts. The paper also discusses in depth the issue of the diverging accuracy of the rental versus capital and total return forecasts

It is important to recognise that it is impossible to isolate the specific source of forecasting error. Whilst econometric models are frequently adopted, judgemental adjustments, non-model-based information, are often made to augment pure 'model' generated forecasts, thus serving to incorporate expert knowledge. Information has value and expert adjustments reflect this. In other words, whilst models attempt to capture the broad systematic influences driving the property variables analysed, a host of other (model omitted) factors will at any point be impacting on rental growth, capital growth and total returns. Both Gallimore \& McAllister (2005) and Watkins et al. (2012) note that most of the firms who provide data to IPF adjust their forecasts. We have no information as to which individual forecasts were purely quantitatively generated and which were subject to overlay adjustments and to what extent. Consequently, when evaluating 'forecast accuracy' we are unable to discern to what extent the measures we employ reflect such subjective adjustments. Correspondingly it is not possible to state categorically where the forecast inaccuracy is originating from and the degree to which either econometric or judgemental forecasts either enhance or distract from the accuracy of the forecasts made. As noted in the paper, biases can (are) introduced, thus rendering the forecasts less accurate than may otherwise have been the case. Indeed, the fact that the Naive Forecasts outperformed the capital value and total return forecasts so frequently does highlight that the use of simple quantitative forecasts would have frequently resulted in greater accuracy.

Whilst we have highlighted a number of possible causes of the forecasting errors observed there remain other factors that may also contribute and are worthy of future consideration. Firstly, whilst the IPF do specify that the respective IPD All Property Indices are the underlying benchmarks it is possible that firms are not directly constructing forecasts of these benchmarks. It may be that an overall forecast is derived from aggregating more specific forecasts. If this is common practice then additional inaccuracy may enter into the forecasting process due to aggregation effects. Secondly, it is 
also worth raising the question of whether forecasters are concentrating too much on modelling fundamental value rather than forecasting what is actually occurring in the market? Potential biases may enter into either 'pure econometric' or 'judgementally enhanced' forecasts if the focus is on the estimation of economically justified returns. If relevant market factors are perceived as nonfundamental, even irrational, and thus excluded from the modelling framework, this may lead to additional forecasting errors being observed. 


\section{References:}

Ager, P., Kappler, M. \& Osterloh, S. (2009). The Accuracy and Efficiency of the Consensus Forecasts: A Further Application and Extension of the Pooled Approach, International Journal of Forecasting, 25, 167-181.

Barber, B.M., Lehavy, R. \& Trueman, B. (2007). Comparing the Stock Recommendation Performance of Investment Banks and Independent Research Firms, Journal of Financial Economics, 85, 490-517.

Batchelor, R. (2007). Bias in Macroeconomic Forecasts, International Journal of Forecasting, 23, 189-203.

Batchelor, R. \& Dua, P. (1991). Blue Chip Rationality Tests, Journal of Money Credit and Banking, 23, 692-705.

Bernhardt, D., Campello, M. \& Kustoati, E. (2006). Who Herds?, Journal of Financial Economics, 80, 657-675.

Bond, S. \& Mitchell, P. (2011). The Information Content of Real Estate Derivative Prices, Journal of Portfolio Management, Special Real Estate Issue, 170-181.

Clarke, J., Ferris, S.P., Jayaraman, N. \& Lee, J. (2006). Are Analyst Recommendations Biased? Evidence from Corporate Bankruptcies, Journal of Financial and Quantitative Analysis, 41, 169-196.

Clarke, J. \& Subramanian, A. (2006). Dynamic Forecasting Behaviour by Analysts: Theory and Evidence, Journal of Financial Economics, 80, 81-113.

Clement, M.B., Hales, J. \& Xue, Y. (2011). Understanding Analysts use of Stock Returns and Other Analysts Revisions when Forecasting Earnings, Journal of Accounting and Economics, 51, 279-299.

Clements, M. (2014). Do US Macroeconomic Forecasters Exaggerate their Differences?, working paper, ICMA Centre, University of Reading.

Clements, M., Joutz, F. \& Stekler, H.O. (2007). An Evaluation of the Forecasts of the Federal Reserve: A Pooled Approach, Journal of Applied Econometrics, 22, 121-136.

Cooper, R.A., Day, T.E. \& Lewis, C.M. (2001). Following the Leader: A Study of Individual Analysts' Earnings Forecasts, Journal of Financial Economics, 61, 383-416.

Cowen, A., Groysberg, B. \& Healy, P. (2006). Which Types of Analyst Firms are More Optimistic?, Journal of Accounting and Economics, 41, 119-146.

Dechow, P.M., Hutton, A.P. \& Sloan, R.G. (2000). The Relation Between Analyst Forecasts of Long Term Earnings Growth and Stock Price Performance Following Equity Offerings, Contemporary Accounting Research, 17, 1-32.

Diebold, F. \& Mariano, R. (1995). Comparing Predictive Accuracy, Journal of Business \& Economic Statistics, 13, 135-144.

Donihue, M.R. (1993). Evaluating the Role Judgment Plays in Forecast Accuracy, Journal of Forecasting, 12, 81-92.

Dovern, J., Fritsche, U. \& Slacalek, J. (2012). Disagreement Among Forecasters in G7 Countries, The Review of Economics and Statistics, 94, 1081-1096.

Dovern, J. \& Weisser, J. (2011). Accuracy, Unbiasedness and Efficiency of Professional Macroeconomic Forecasts: An Empirical Comparison for the G7, International Journal of Forecasting, 27, 452-465.

Ehrbeck, T. \& Waldmann, R. (1996). Why are Professional Forecasts Biased? Agency Versus Behavioral Explanations, Quarterly Journal of Economics, 111, 21.40.

Elliot, G., Komunjer, I. \& Timmermann, A. (2008). Biases in Macroeconomic Forecasters: Irrationality or Asymmetric Loss?, Journal of the European Economic Association, 6, 122-157. 
Fintzen, D. \& Stekler, H.O. (1999). Why Did Forecasters Fail to Predict the 1990 Recession?, International Journal of Forecasting, 15, 309-323.

Gallimore, P. \& McAllister, P. (2005). Expert Judgement in the Processes of Commercial Property Market Forecasting, Journal of Property Research, 21, 337-360.

Geltner, D. (1991). Smoothing in Appraisal Based Returns, Journal of Real Estate Finance \& Economics, 4, 327-345.

Geltner, D. (1993). Temporal Aggregation in Real Estate Return Indices, AREUEA Journal, 21, 141 166.

Gjaltema, A. (2001). Judgment in (Population) Forecasting, Paper presented at European Population Conference, Helsinki 2001.

Granger, C. \& Pesaran, H. (1999). Economic and Statistical Measures of Forecast Accuracy, Journal of Forecasting, 19, 537-560.

Hendry, D. \& Clements, M. (2003). Economic Forecasting: Some Lessons from Recent Research, Economic Modeling, 20, 301-329.

Hong, H. \& Kubik, J.D. (2003). Analyzing the Analysts: Career Concerns and Biased Earnings Forecasts, Journal of Finance, 58, 313-351.

Isiklar, G., Lahiri, K. \& Loungani, P. (2006). How Quickly do Forecasters Incorporate News? Evidence from Cross-Country Surveys, Journal of Applied Econometrics, 21, 703-725.

Isiklar, G. \& Lahiri, K. (2007). How Far Ahead Can We Forecast? Evidence from Cross-Country Surveys, International Journal of Forecasting, 23, 167-187.

Jonung, L. \& Larch, M. (2006). Improving Fiscal Policy in the EU. The Case for Independent Forecasts, Economic Policy, 21, 491-534.

Jung, B., Shane, P.B. \& Yang, Y.S. (2012). Do Financial Analysts' Long-Term Growth Forecasts Matter? Evidence from Stock Recommendations and Career Outcomes, Journal of Accounting and Economics, 53, 55-76.

Kim, Y., Lobo, G.J. \& Song, M. (2011). Analyst Characteristics, Timing of Forecast Revisions and Analyst Forecasting Ability, Journal of Banking \& Finance, 35, 2158-2168.

Lahiri, K. \& Sheng, X. (2008). Evolution of Forecast Disagreement in a Bayesian Learning Model, Journal of Econometrics, 144, 325-340

Lahiri, K. \& Sheng, X. (2010). Measuring Forecast Uncertainty by Disagreement: The Missing Link, Journal of Applied Econometrics, 25, 514-538

Lamont, O.A. (2002). Macroeconomic Forecasts and Microeconomic Forecasters. Journal of Economic Behavior \& Organization, 48, 265-280.

Laster, D., Bennett, P. \& Geoum, I. (1999) Rational Bias in Macroeconomic Forecasts, Quarterly Journal of Economics, 114, 293-318.

Lawrence, M., Goodwin, P., O’Connor, M. \& Onkal, D. (2006). Judgmental Forecasting: A Review of Progress over the Last 25 Years, International Journal of Forecasting, 22, 493-518.

Linden, S. (2003). Assessment of GDP Forecast Uncertainty, European Commission Economic Papers.

Ling, D. (2005). A Random Walk Down Main Street: Can Experts Predict Returns on Commercial Real Estate? Journal of Real Estate Research, 27, 137-154.

McAllister, P., Newell, G. \& Matysiak, G. (2008). Agreement and Accuracy in Consensus Forecasts of the UK Commercial Property Market, Journal of Property Research, 25, 1-22.

McNees, S.K. (1990). The Role of Judgment in Macroeconomic Forecasting Accuracy, International Journal of Forecasting, 6, 287-299. 
Mensah, Y.M. \& Yang, R. (2008). An Empirical Evaluation of Analysts' Herding Behavior Following Regulation Fair Disclosure, Journal of Accounting and Public Policy, 27, 317-338.

Mincer, J. \& Zarnowitz, V., (1969). The Evaluation of Economic Forecasts, in: Mincer J., ed., Economic Forecasts and Expectations, National Bureau of Economic Research, New York.

Oller, E. \& Barot, B. (2000). The Accuracy of European Growth and Inflation Forecasts, International Journal of Forecasting, 16, 293-315.

Ottaviani, M. \& Sorensen, P.N. (2006). The Strategy of Professional Forecasting, Journal of Financial Economics, 81, 441-466.

Patton, A.J. \& Timmermann, A. (2010). Why do Forecasters Disagree? Lessons from the Term Structure of Cross-Sectional Dispersion, Journal of Monetary Economics, 57, 803-820.

Pierdzioch, C., Rulke, J.C. \& Stadtmann, G. (2012). Housing Starts in Canada, Japan and the United States: Do Forecasters Herd?, Journal of Real Estate Finance \& Economics, 45, 754-773.

Pons-Novell, J. (2003). Strategic Bias, Herding Behavior and Economic Forecasts, Journal of Forecasting, 22, 67-77.

Samuelson, P. (1976). Optimality of Sluggish Predictors under Ergodic Probabilities, International Economic Review, 17, 1-17.

Scotese, C.A. (1994). Forecast Smoothing and the Optimal Underutilization of Information at the Federal Reserve, Journal of Macroeconomics, 16, 653-670.

Smyth, D. \& Ash, J. C. K. (1981). The Underestimation of Forecasts and the Variability of Predictions and Outcomes, Bulletin of Economic Research, 33, 37-44.

Stekler, H.O. (2007). The Future of Macroeconomic Forecasting: Understanding the Forecasting Process, International Journal of Forecasting, 23, 237-248.

Stevenson, S., Akimov, A., Hutson, E. \& Krystalogianni, A. (2014). Commonalities in Global Office Market Cycles, Regional Studies, 48, 456-470.

Stock, J. \& Watson, M. (1993). A Procedure for Predicting Recessions with Leading Indicators: Econometric Issues and Recent Experience, in Stock J. and Watson M., Business Cycles, Indicators and Forecasting, National Bureau of economic Research Studies in Business Cycles, vol. 28, University of Chicago Press, pp. 95-156.

Theil, H. (1966).Applied Economic Forecasting, North Holland, Amsterdam.

Theil, H. (1971). Principles of Econometrics, North Holland, Amsterdam.

Tillman, P. (2011). Strategic Forecasting on the FOMC, European Journal of Political Economy, 27, 547-553.

Watkins, C., White, M. \& Keskin, B. (2012). The Future of Property Forecasting, Report for the Investment Property Forum.

Welch, I. (2000). Herding Among Security Analysts, Journal of Financial Economics, 58, 369-396.

Zarnowitz, V. \& Braun, P. (1993). Twenty two years of the NBER-ASA Quarterly Outlook Surveys: Aspects and comparisons of forecasting performance, University of Chicago Press, pp. 11-94. 
Tables and Figures

Table 1: Composition of the Annual IPD All Property Index

\begin{tabular}{lcc}
\hline & $\begin{array}{c}\text { Capital } \\
\text { Value (£m) }\end{array}$ & $\begin{array}{c}\text { \% Capital } \\
\text { Value }\end{array}$ \\
\hline All Retail & $\mathbf{7 4 , 8 5 0}$ & $\mathbf{5 0 . 5 1 \%}$ \\
Standard Retail (South East of England) & 12,585 & $8.49 \%$ \\
Standard Retail (Rest of UK) & 11,162 & $7.53 \%$ \\
Shopping Centres & 24,936 & $16.83 \%$ \\
\hline All Offices & $\mathbf{4 1 , 4 9 8}$ & $\mathbf{2 8 . 0 0 \%}$ \\
City of London & 7,572 & $5.11 \%$ \\
West End of London & 18,153 & $12.25 \%$ \\
Rest of South East of England & 9,757 & $6.58 \%$ \\
Rest of UK & 6,016 & $4.06 \%$ \\
\hline All Industrial & $\mathbf{2 0 , 2 4 8}$ & $\mathbf{1 3 . 6 6 \%}$ \\
South East of England & 12,061 & $8.14 \%$ \\
Rest of UK & 8,187 & $5.52 \%$ \\
\hline Other Property & $\mathbf{1 1 , 5 9 3}$ & $\mathbf{7 . 8 2 \%}$ \\
All Property & $\mathbf{1 4 8 , 1 8 9}$ & $\mathbf{1 0 0 . 0 0 \%}$ \\
\hline
\end{tabular}

Notes: Table 1 provides details of the composition of the Annual IPD All Property Index for the UK for 2011. 
Table 2: Performance of Consensus and Individual Forecasts

\begin{tabular}{|c|c|c|c|c|c|c|c|c|c|c|c|c|c|c|}
\hline & & 2000 & 2001 & 2002 & 2003 & 2004 & 2005 & 2006 & 2007 & 2008 & 2009 & 2010 & 2011 & $\begin{array}{l}\text { Standard } \\
\text { Deviation }\end{array}$ \\
\hline \multirow{9}{*}{$\begin{array}{l}\text { One-Year Rental } \\
\text { Growth Forecasts. }\end{array}$} & Actual Outcome & 7.40 & 3.60 & -1.20 & -2.00 & 2.10 & 2.90 & 4.00 & 4.70 & -1.20 & -7.90 & -0.50 & 0.60 & 3.99 \\
\hline & Consensus Forecast & 4.00 & 4.50 & 1.30 & 0.20 & -0.60 & 2.00 & 2.40 & 3.50 & 2.60 & -6.30 & -6.10 & 1.04 & 3.55 \\
\hline & Maximum & 6.50 & 7.10 & 3.50 & 2.20 & 0.70 & 3.10 & 3.70 & 5.00 & 5.30 & -2.10 & -1.90 & 3.60 & \\
\hline & Minimum & 2.00 & 2.60 & -2.00 & -2.00 & -2.10 & 0.60 & 0.60 & 2.60 & 1.10 & -10.80 & -12.80 & -0.70 & \\
\hline & Range & 4.50 & 4.50 & 5.50 & 4.20 & 2.80 & 2.50 & 3.10 & 2.40 & 4.20 & 8.70 & 10.90 & 4.30 & \\
\hline & MFE & 3.43 & -0.91 & -2.55 & -2.16 & 2.64 & 0.87 & 1.61 & 1.22 & -3.78 & -1.55 & 5.63 & -0.44 & \\
\hline & Skewness & 0.70 & 0.50 & -1.00 & -0.50 & -0.40 & -0.10 & -0.80 & 0.50 & 1.00 & -0.30 & -0.90 & 0.74 & \\
\hline & Jacque-Bera & 2.30 & 1.50 & 4.30 & 1.10 & 1.90 & 0.30 & $6.30^{\mathrm{a}}$ & 1.90 & $6.10^{\mathrm{a}}$ & 0.60 & $6.20^{\mathrm{a}}$ & $6.54^{\mathrm{a}}$ & \\
\hline & No. Observations & 28 & 28 & 25 & 18 & 21 & 27 & 28 & 29 & 29 & 23 & 27 & 27 & \\
\hline \multirow{9}{*}{$\begin{array}{l}\text { One-Year Capital } \\
\text { Value Growth } \\
\text { Forecasts }\end{array}$} & Actual Outcome & 3.60 & 0.10 & 2.60 & 3.90 & 11.40 & 12.80 & 12.60 & -7.70 & -26.32 & -3.60 & 8.30 & 1.90 & 10.84 \\
\hline & Consensus Forecast & 5.00 & 3.70 & 0.70 & 0.50 & 0.00 & 2.40 & 2.80 & 2.60 & -3.78 & -11.40 & 2.40 & -1.54 & 4.38 \\
\hline & Maximum & 9.50 & 7.00 & 3.30 & 3.50 & 3.00 & 5.00 & 7.20 & 7.00 & 3.00 & -5.00 & 11.00 & 3.53 & \\
\hline & Minimum & 2.00 & 1.00 & -4.00 & -2.00 & -2.00 & -3.00 & -1.00 & -1.60 & -9.40 & -20.60 & -7.20 & -9.40 & \\
\hline & Range & 7.50 & 6.00 & 7.30 & 5.50 & 5.00 & 8.00 & 8.20 & 8.60 & 12.40 & 15.60 & 18.20 & 12.93 & \\
\hline & MFE & -1.40 & -3.61 & 1.86 & 3.32 & 11.40 & 10.38 & 9.80 & -10.34 & -22.54 & 7.80 & 5.83 & 3.44 & \\
\hline & Skewness & 0.60 & 0.40 & -0.90 & 0.20 & 0.80 & -1.50 & -0.70 & -0.10 & 0.50 & -0.60 & -0.20 & -0.92 & \\
\hline & Jacque-Bera & 1.70 & 0.70 & 3.80 & 0.60 & 3.20 & $29.40^{\mathrm{a}}$ & $10.17^{\mathrm{a}}$ & 0.20 & 1.70 & 1.40 & 0.80 & 3.78 & \\
\hline & No. Observations & 28 & 28 & 25 & 18 & 21 & 27 & 28 & 30 & 30 & 23 & 27 & 26 & \\
\hline \multirow{9}{*}{$\begin{array}{l}\text { One-Year Total } \\
\text { Return Forecasts }\end{array}$} & Actual Outcome & 10.45 & 6.79 & 9.64 & 10.85 & 18.33 & 19.10 & 18.10 & -3.42 & -22.10 & 3.51 & 15.09 & 7.80 & 11.51 \\
\hline & Consensus Forecast & 11.74 & 10.70 & 7.85 & 7.59 & 6.89 & 8.98 & 8.69 & 7.59 & 1.15 & -5.20 & 10.02 & 5.19 & 4.66 \\
\hline & Maximum & 16.00 & 14.00 & 11.00 & 11.00 & 9.00 & 12.00 & 13.00 & 12.00 & 8.00 & 1.00 & 19.00 & 10.35 & \\
\hline & Minimum & 8.70 & 8.00 & 3.50 & 5.00 & 5.00 & 4.00 & 5.00 & 3.20 & -4.80 & -14.30 & -0.60 & -2.40 & \\
\hline & Range & 7.60 & 6.00 & 7.00 & 5.50 & 4.40 & 8.00 & 7.70 & 8.80 & 13.10 & 14.90 & 19.60 & 12.75 & \\
\hline & MFE & -1.29 & -3.91 & 1.79 & 3.27 & 11.44 & 10.12 & 9.42 & -11.01 & -23.25 & 8.71 & 5.08 & 2.61 & \\
\hline & Skewness & 0.80 & 0.40 & -0.60 & -0.10 & 0.40 & -1.10 & -0.60 & -0.10 & 0.40 & -0.60 & -0.20 & -0.95 & \\
\hline & Jacque-Bera & 2.70 & 1.70 & 1.80 & 0.60 & 0.80 & $17.70^{\mathrm{a}}$ & $8.25^{\mathrm{b}}$ & 0.50 & 0.70 & 1.20 & 1.90 & 4.13 & \\
\hline & No. Observations & 28 & 28 & 25 & 18 & 21 & 27 & 28 & 30 & 30 & 23 & 26 & 26 & \\
\hline
\end{tabular}


Table 2: Performance of Consensus and Individual Forecasts (continued)

\begin{tabular}{|c|c|c|c|c|c|c|c|c|c|c|c|c|c|}
\hline & & 2001 & 2002 & 2003 & 2004 & 2005 & 2006 & 2007 & 2008 & 2009 & 2010 & 2011 & $\begin{array}{l}\text { Standard } \\
\text { Deviation }\end{array}$ \\
\hline \multirow{9}{*}{$\begin{array}{l}\text { Two-Year Rental } \\
\text { Growth Forecasts }\end{array}$} & Actual Outcome & 3.60 & -1.20 & -2.00 & 2.10 & 2.90 & 4.00 & 4.70 & -1.20 & -7.90 & -0.50 & 0.60 & 3.62 \\
\hline & Consensus Forecast & 3.90 & 3.70 & 2.40 & 1.80 & 1.20 & 2.60 & 2.70 & 3.10 & 2.10 & -4.10 & -1.00 & 2.33 \\
\hline & Maximum & 7.00 & 7.00 & 5.00 & 4.00 & 3.00 & 4.00 & 3.70 & 4.50 & 5.30 & 0.80 & 4.40 & \\
\hline & Minimum & 2.00 & 1.40 & 0.00 & 0.00 & -1.00 & 1.00 & 1.40 & 1.50 & -0.10 & -12.00 & -4.30 & \\
\hline & Range & 5.00 & 5.60 & 5.00 & 4.00 & 4.00 & 3.00 & 2.30 & 3.00 & 5.40 & 12.80 & 8.70 & \\
\hline & MFE & -0.37 & -4.91 & -4.36 & 0.25 & 1.67 & 1.41 & 2.07 & -4.31 & -9.93 & 3.64 & 1.60 & \\
\hline & Skewness & 0.80 & 0.80 & -0.20 & 0.30 & -0.40 & 0.10 & -0.1 & -0.50 & 0.60 & -1.00 & 1.25 & \\
\hline & Jacque-Bera & 3.20 & 2.70 & 0.30 & 0.30 & 0.90 & 0.10 & 0.30 & 1.10 & 5.90 & 4.80 & $46.61^{\mathrm{a}}$ & \\
\hline & No. Observations & 27 & 28 & 25 & 17 & 20 & 26 & 28 & 29 & 29 & 23 & 27 & \\
\hline \multirow{9}{*}{$\begin{array}{l}\text { Two-Year Capital } \\
\text { Value Growth } \\
\text { Forecasts }\end{array}$} & Actual Outcome & 0.10 & 2.60 & 3.90 & 11.40 & 12.80 & 12.60 & -7.70 & -26.30 & -3.60 & 8.30 & 1.90 & 11.35 \\
\hline & Consensus Forecast & 4.70 & 3.10 & 2.50 & 2.20 & 0.90 & 1.70 & 1.10 & -0.15 & 0.70 & -0.74 & 2.17 & 1.53 \\
\hline & Maximum & 10.50 & 7.00 & 6.00 & 5.00 & 2.80 & 4.00 & 4.30 & 4.60 & 5.20 & 5.50 & 12.80 & \\
\hline & Minimum & 1.00 & 0.70 & 0.00 & 0.00 & -1.20 & -1.50 & -2.10 & -5.00 & -5.90 & -11.60 & -2.60 & \\
\hline & Range & 9.50 & 6.30 & 6.00 & 5.00 & 4.00 & 5.50 & 6.40 & 9.60 & 11.10 & 17.10 & 15.40 & \\
\hline & MFE & -4.60 & -0.48 & 1.34 & 9.21 & 11.85 & 10.90 & -8.80 & -26.18 & -4.31 & 8.99 & -0.27 & \\
\hline & Skewness & -0.94 & 0.79 & 0.23 & 0.11 & -0.15 & -0.46 & -0.20 & -0.60 & -0.71 & -1.16 & 1.34 & \\
\hline & Jacque-Bera & $13.10^{\mathrm{a}}$ & 2.90 & 0.30 & 0.00 & 0.20 & 1.00 & 0.20 & 2.00 & 4.10 & $11.20^{\mathrm{a}}$ & $23.65^{\mathrm{a}}$ & \\
\hline & No. Observations & 27 & 28 & 25 & 17 & 20 & 26 & 28 & 29 & 29 & 23 & 27 & \\
\hline \multirow{9}{*}{$\begin{array}{l}\text { Two-Year Total } \\
\text { Return Forecasts }\end{array}$} & Actual Outcome & 6.79 & 9.64 & 10.85 & 18.33 & 19.10 & 18.10 & -3.42 & -22.10 & 3.51 & 15.09 & 7.80 & 12.04 \\
\hline & Consensus Forecast & 11.40 & 10.20 & 9.80 & 9.40 & 7.90 & 8.20 & 6.90 & 4.80 & 5.90 & 6.20 & 9.43 & 2.06 \\
\hline & Maximum & 16.50 & 15.00 & 13.00 & 12.60 & 9.70 & 11.00 & 10.00 & 9.00 & 10.00 & 12.00 & 21.10 & \\
\hline & Minimum & 9.00 & 7.40 & 6.70 & 7.10 & 5.50 & 5.00 & 3.60 & 0.10 & 0.10 & -4.80 & 3.50 & \\
\hline & Range & 7.50 & 7.60 & 6.30 & 5.50 & 4.20 & 6.00 & 6.40 & 8.90 & 9.90 & 16.80 & 17.60 & \\
\hline & MFE & -4.61 & -0.53 & 1.03 & 8.95 & 11.22 & 9.90 & -10.36 & -26.94 & -2.39 & 8.94 & -1.63 & \\
\hline & Skewness & 1.28 & 0.76 & 0.19 & 0.63 & -0.43 & -0.33 & -0.39 & -0.64 & -0.62 & -1.06 & 1.33 & \\
\hline & Jacque-Bera & $18.10^{\mathrm{a}}$ & 3.20 & 0.40 & 1.20 & 0.80 & 0.70 & 0.70 & 2.20 & 2.10 & $7.10^{\mathrm{a}}$ & $25.86^{\mathrm{a}}$ & \\
\hline & No. Observations & 27 & 28 & 25 & 17 & 20 & 26 & 28 & 30 & 29 & 23 & 26 & \\
\hline
\end{tabular}

Notes: Table 2 reports the actual annual return of the respective Annual IPD All Property Index, the IPF consensus forecast for that year and the number of forecasts that comprise the consensus.

Summary statistics for the individual forecasts are also provided. 


\section{Figure 1: Accuracy of the Consensus Property Forecasts}

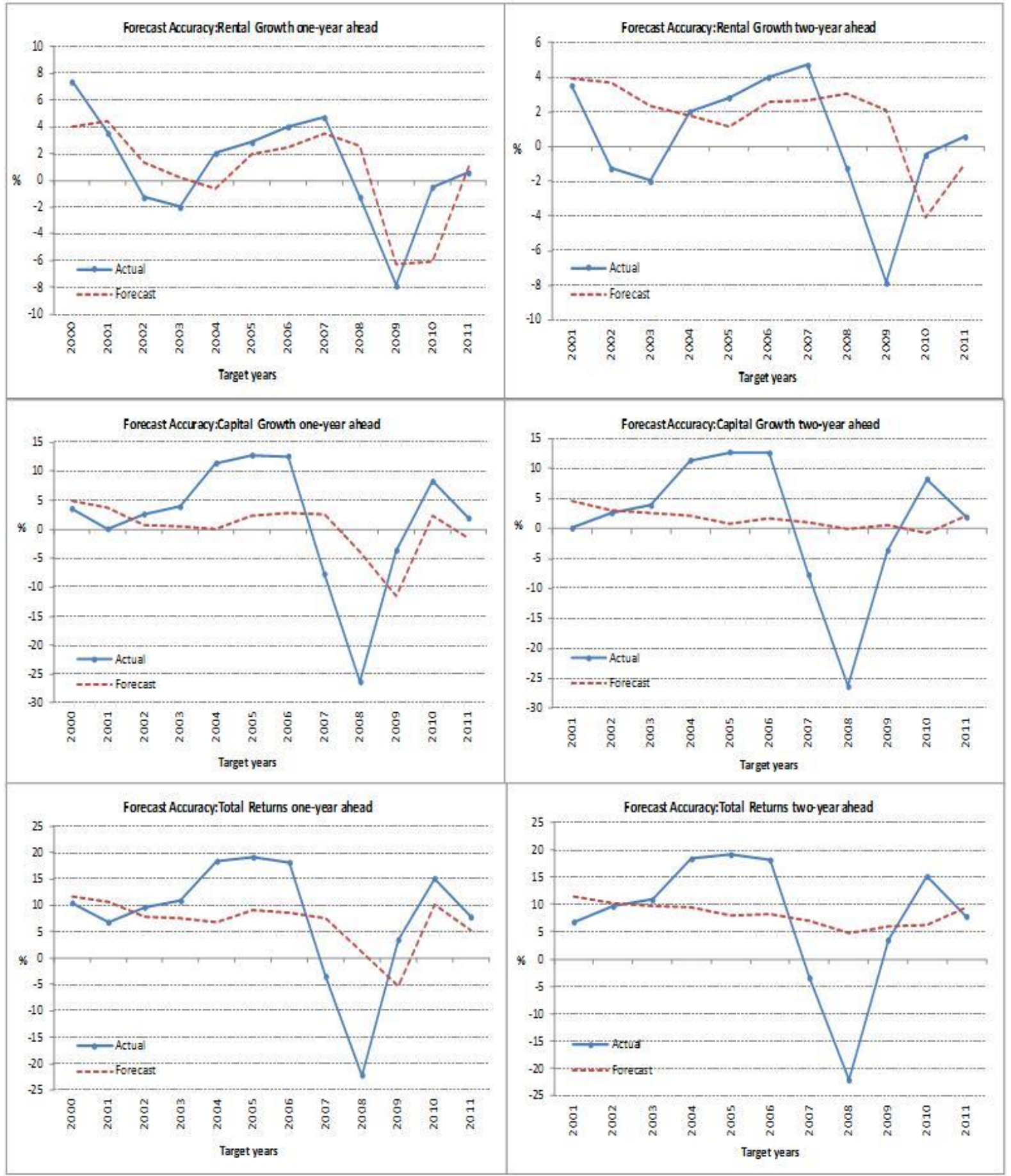

Notes: Figure 1 displays the actual growth rates for the respective IPD indices together with the corresponding IPF Consensus Forecasts. 
Table 3: Forecast Errors of the one and two year ahead forecasts

\begin{tabular}{|c|c|c|c|c|c|c|c|c|c|c|}
\hline & & \multicolumn{3}{|c|}{ Rental Growth } & \multicolumn{3}{|c|}{ Capital Growth } & \multicolumn{3}{|c|}{ Total Returns } \\
\hline \multicolumn{11}{|c|}{ Panel A: One-Year Forecasts } \\
\hline Forecast & Target & MAE & MSE & RMSE & MAE & MSE & RMSE & MAE & MSE & RMSE \\
\hline 1999 & 2000 & 3.43 & 13.13 & 3.62 & 1.75 & 5.32 & 2.31 & 1.58 & 4.79 & 2.19 \\
\hline 2000 & 2001 & 1.24 & 2.54 & 1.59 & 3.61 & 15.15 & 3.89 & 3.91 & 18.08 & 4.25 \\
\hline 2001 & 2002 & 2.73 & 8.80 & 2.97 & 2.00 & 7.11 & 2.67 & 2.02 & 7.02 & 2.65 \\
\hline 2002 & 2003 & 2.16 & 5.99 & 2.45 & 3.32 & 13.49 & 3.67 & 3.27 & 13.06 & 3.61 \\
\hline 2003 & 2004 & 2.64 & 7.82 & 2.80 & 11.40 & 131.32 & 11.46 & 11.44 & 132.17 & 11.50 \\
\hline 2004 & 2005 & 0.91 & 1.16 & 1.08 & 10.38 & 110.15 & 10.50 & 10.12 & 104.76 & 10.24 \\
\hline 2005 & 2006 & 1.61 & 2.96 & 1.72 & 9.80 & 98.44 & 9.92 & 9.42 & 90.92 & 9.54 \\
\hline 2006 & 2007 & 1.24 & 1.77 & 1.33 & 10.34 & 110.72 & 10.52 & 11.01 & 124.84 & 11.17 \\
\hline 2007 & 2008 & 3.78 & 15.25 & 3.91 & 22.54 & 516.13 & 22.72 & 23.25 & 549.86 & 23.45 \\
\hline 2008 & 2009 & 2.36 & 7.60 & 2.76 & 7.80 & 76.24 & 8.73 & 8.71 & 90.85 & 9.53 \\
\hline 2009 & 2010 & 5.63 & 36.93 & 6.08 & 6.03 & 47.99 & 6.93 & 5.46 & 41.19 & 6.42 \\
\hline 2010 & 2011 & 0.73 & 0.93 & 0.96 & 3.64 & 22.31 & 4.72 & 3.04 & 17.12 & 4.14 \\
\hline \multicolumn{11}{|c|}{ Panel B: Two-Year Forecasts } \\
\hline Forecast & Target & MAE & MSE & RMSE & MAE & MSE & RMSE & MAE & MSE & RMSE \\
\hline 1999 & 2001 & 0.95 & 1.55 & 1.25 & 4.59 & 24.34 & 4.93 & 4.63 & 23.85 & 4.88 \\
\hline 2000 & 2002 & 4.91 & 25.99 & 5.10 & 1.25 & 2.72 & 1.65 & 1.42 & 3.31 & 1.82 \\
\hline 2001 & 2003 & 4.36 & 20.77 & 4.56 & 1.70 & 4.11 & 2.03 & 1.59 & 3.50 & 1.87 \\
\hline 2002 & 2004 & 0.84 & 1.12 & 1.06 & 9.21 & 86.51 & 9.30 & 8.95 & 82.19 & 9.07 \\
\hline 2003 & 2005 & 1.69 & 3.58 & 1.89 & 11.85 & 141.56 & 11.90 & 11.22 & 127.03 & 11.27 \\
\hline 2004 & 2006 & 1.41 & 2.51 & 1.59 & 10.90 & 120.77 & 10.99 & 9.90 & 100.34 & 10.02 \\
\hline 2005 & 2007 & 2.07 & 4.66 & 2.16 & 8.80 & 79.68 & 8.93 & 10.36 & 109.47 & 10.46 \\
\hline 2006 & 2008 & 4.31 & 19.16 & 4.38 & 26.18 & 690.05 & 26.27 & 26.94 & 730.04 & 27.02 \\
\hline 2007 & 2009 & 9.93 & 99.68 & 9.98 & 4.46 & 23.82 & 4.88 & 2.91 & 10.91 & 3.30 \\
\hline 2008 & 2010 & 3.84 & 23.48 & 4.85 & 8.99 & 93.75 & 9.68 & 8.94 & 95.15 & 9.75 \\
\hline 2009 & 2011 & 1.88 & 4.80 & 2.19 & 2.33 & 9.64 & 3.11 & 2.77 & 14.15 & 3.76 \\
\hline
\end{tabular}

Notes: MAE, MSE and RMSE are the Mean Absolute Error, Mean Squared Error and the Root Mean Squared Error respectively. Figures in bold indicate the year of highest forecast errors for rental growth, capital growth and total returns. 
Table 4: Correlations between Consensus Forecasts and Actual Values

\begin{tabular}{lcccc}
\hline Variable & Forecast & Correlation & t-stat & Conclusion \\
\hline Rental Growth & 1year ahead & $0.74 * * *$ & 3.48 & Significant \\
& 2year ahead & 0.09 & 0.28 & Insignificant \\
Capital Growth & 1year ahead & 0.42 & 1.47 & Insignificant \\
& 2year ahead & 0.24 & 0.75 & Insignificant \\
Total Return & 1year ahead & 0.50 & 1.81 & Insignificant \\
& 2year ahead & 0.50 & 1.73 & Insignificant \\
\hline
\end{tabular}

Notes: Table 4 reports the correlation coefficients between the actual and forecasted returns based on the noted horizon. $* * *$ indicates a $1 \%$ level of significance. 
Figure 2: Distribution of one-year Ahead Forecasts

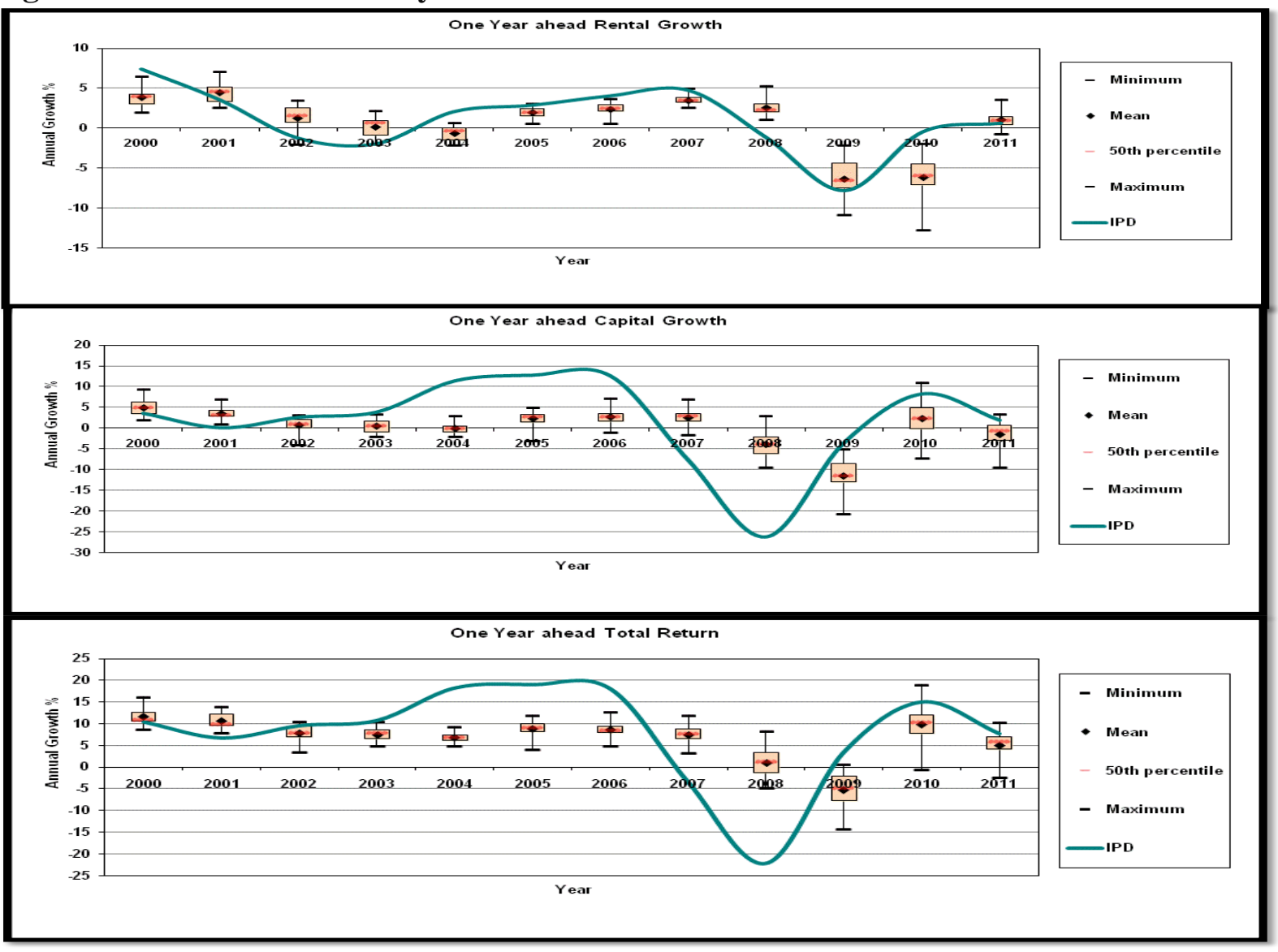

Notes: Figure 2 displays box-whisker plots for the one-year forecasts of rental growth, capital returns and total returns. 
Figure 3: Distribution of two-year Ahead Forecasts
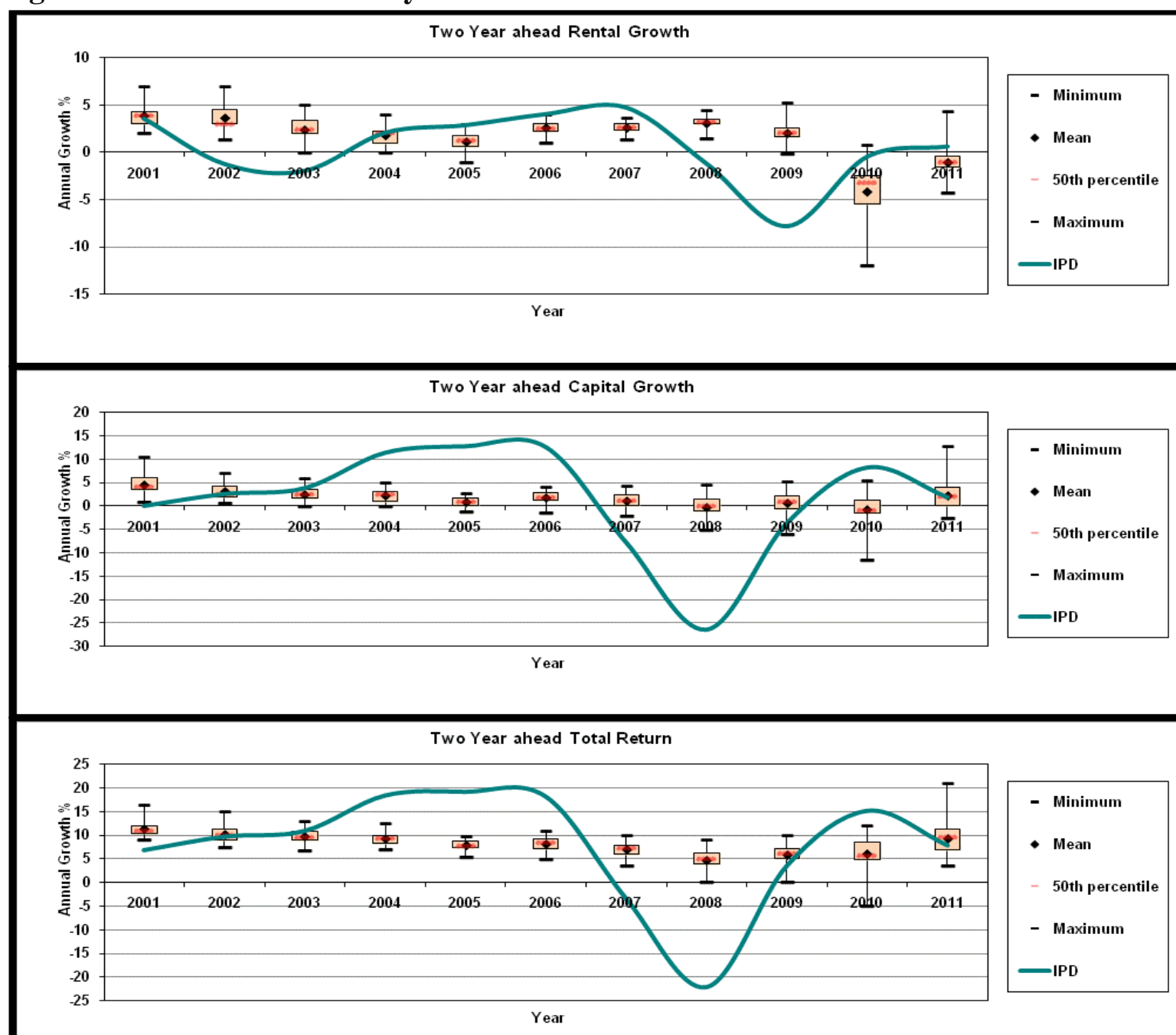

Notes: Figure 3 displays box-whisker plots for the two-year forecasts of rental growth, capital returns and total returns. 
Table 5: Theil's U2 statistic for Comparative Performance versus Naive Forecasts

\begin{tabular}{|c|c|c|c|c|c|c|c|}
\hline \multirow[t]{2}{*}{ Forecast } & \multirow[t]{2}{*}{ Target } & \multicolumn{3}{|c|}{ Naive 1} & \multicolumn{3}{|c|}{ Naive 2} \\
\hline & & $\begin{array}{l}\text { Rental } \\
\text { Growth }\end{array}$ & $\begin{array}{c}\text { Capital } \\
\text { Value }\end{array}$ & $\begin{array}{c}\text { Total } \\
\text { Returns }\end{array}$ & $\begin{array}{c}\text { Rental } \\
\text { Growth }\end{array}$ & $\begin{array}{c}\text { Capital } \\
\text { Value }\end{array}$ & $\begin{array}{c}\text { Total } \\
\text { Returns }\end{array}$ \\
\hline \multicolumn{8}{|c|}{ Panel A: One-Year Ahead Forecasts } \\
\hline 1999 & 2000 & 1.95 & 0.63 & 0.54 & 1.35 & 82.64 & 17.82 \\
\hline 2000 & 2001 & 0.42 & 1.12 & 1.16 & 1.33 & 1.05 & 1.06 \\
\hline 2001 & 2002 & 0.62 & 1.05 & 0.93 & 0.48 & 2.30 & 2.35 \\
\hline 2002 & 2003 & 3.33 & 2.92 & 2.97 & 0.36 & 13.30 & 13.07 \\
\hline 2003 & 2004 & 0.69 & 1.52 & 1.54 & 1.12 & 1.46 & 1.47 \\
\hline 2004 & 2005 & 1.34 & 7.66 & 13.37 & 0.77 & 1.14 & 1.20 \\
\hline 2005 & 2006 & 1.47 & 63.68 & 9.57 & 12.41 & 1.14 & 1.32 \\
\hline 2006 & 2007 & 1.91 & 0.52 & 0.52 & 2.19 & 0.88 & 0.76 \\
\hline 2007 & 2008 & 0.66 & 1.22 & 1.26 & 0.73 & 0.74 & 0.70 \\
\hline 2008 & 2009 & 0.42 & 0.38 & 0.37 & 0.23 & 1.13 & 1.29 \\
\hline 2009 & 2010 & 0.82 & 0.58 & 0.55 & 1.38 & 1.32 & 1.20 \\
\hline 2010 & 2011 & 0.90 & 0.74 & 0.57 & 0.33 & 5.31 & 2.40 \\
\hline \multicolumn{8}{|c|}{ Panel B: Two-Year Ahead Forecasts } \\
\hline 1999 & 2001 & 0.63 & 0.69 & 0.63 & 1.08 & 1.40 & 1.29 \\
\hline 2000 & 2002 & 0.59 & 1.74 & 2.23 & 0.85 & 1.41 & 1.59 \\
\hline 2001 & 2003 & 0.82 & 0.53 & 0.46 & 0.66 & 20.25 & 21.50 \\
\hline 2002 & 2004 & 0.32 & 1.06 & 1.04 & 0.38 & 1.19 & 1.17 \\
\hline 2003 & 2005 & 0.39 & 1.34 & 1.37 & 1.12 & 1.29 & 1.32 \\
\hline 2004 & 2006 & 0.80 & 9.05 & 43.44 & 6.87 & 1.21 & 1.33 \\
\hline 2005 & 2007 & 1.15 & 0.44 & 0.46 & 3.88 & 0.77 & 0.73 \\
\hline 2006 & 2008 & 0.83 & 0.67 & 0.67 & 0.82 & 0.86 & 0.81 \\
\hline 2007 & 2009 & 0.79 & 1.19 & 0.48 & 0.83 & 0.60 & 0.41 \\
\hline 2008 & 2010 & 6.48 & 0.28 & 0.26 & 1.05 & 2.33 & 2.33 \\
\hline 2009 & 2011 & 0.26 & 0.56 & 0.88 & 0.65 & 2.78 & 1.94 \\
\hline
\end{tabular}

Notes: Naive 1 approach indicates the previous year growth-rate for the rental growth, capital growth and total returns and the Naive 2 is the long-term average of the actual values of the three property variables up to the date of forecasts. Figures in bold indicate consensus forecasts were more accurate than naive forecasts, in that the Theil U2 statistic is less than unity. 
Table 6: Summary of Consensus Forecasts Performance versus Naive

\begin{tabular}{ccccccc}
\hline & $\begin{array}{c}\text { Rental } \\
\text { Growth }\end{array}$ & & $\begin{array}{c}\text { Capital } \\
\text { Value }\end{array}$ & \multicolumn{3}{c}{$\begin{array}{c}\text { Total } \\
\text { Returns }\end{array}$} \\
\hline Naive 1 & 1 Year & 2 Year & 1 Year & 2 Year & 1 Year & 2 Year \\
Naive 2 & $6(50 \%)$ & $5(45.45 \%)$ & $10(83.33 \%)$ & $8(72.73 \%)$ & $10(83.33 \%)$ & $8(72.73 \%)$ \\
\hline
\end{tabular}

Notes: Table 6 reports the number of years in which the respective naive forecast outperformed the IPF Consensus. These are out of a total of 12 one-year ahead forecasts and 11 two-year estimates. The figures in parentheses report the percentage of years in which the naive forecasts outperformed. Naive 1 approach indicates the previous year growth-rate for the rental growth, capital growth and total returns and the Naive 2 is the long-term average of the actual values of the three property variables up to the date of forecasts. The relative performance is based upon the Theil U2 statistics reported in Table 5. 


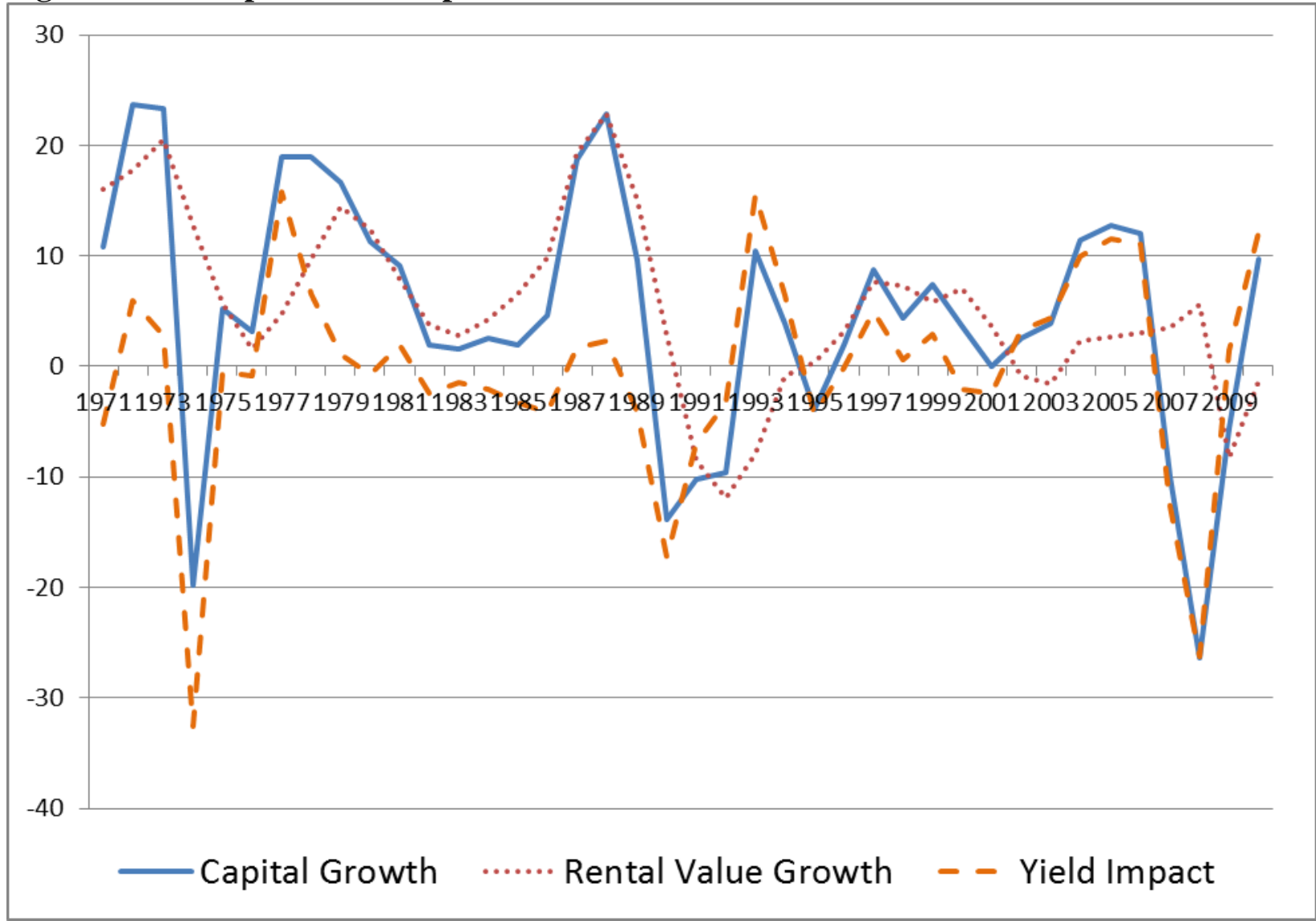

Notes: Figure 4 shows the annual returns of the IPD capital and rental value series and the annual all property IPD Yield Impact series. 
Figure 5: Implied Capital Value Changes based on Under-Estimated Yield Movements

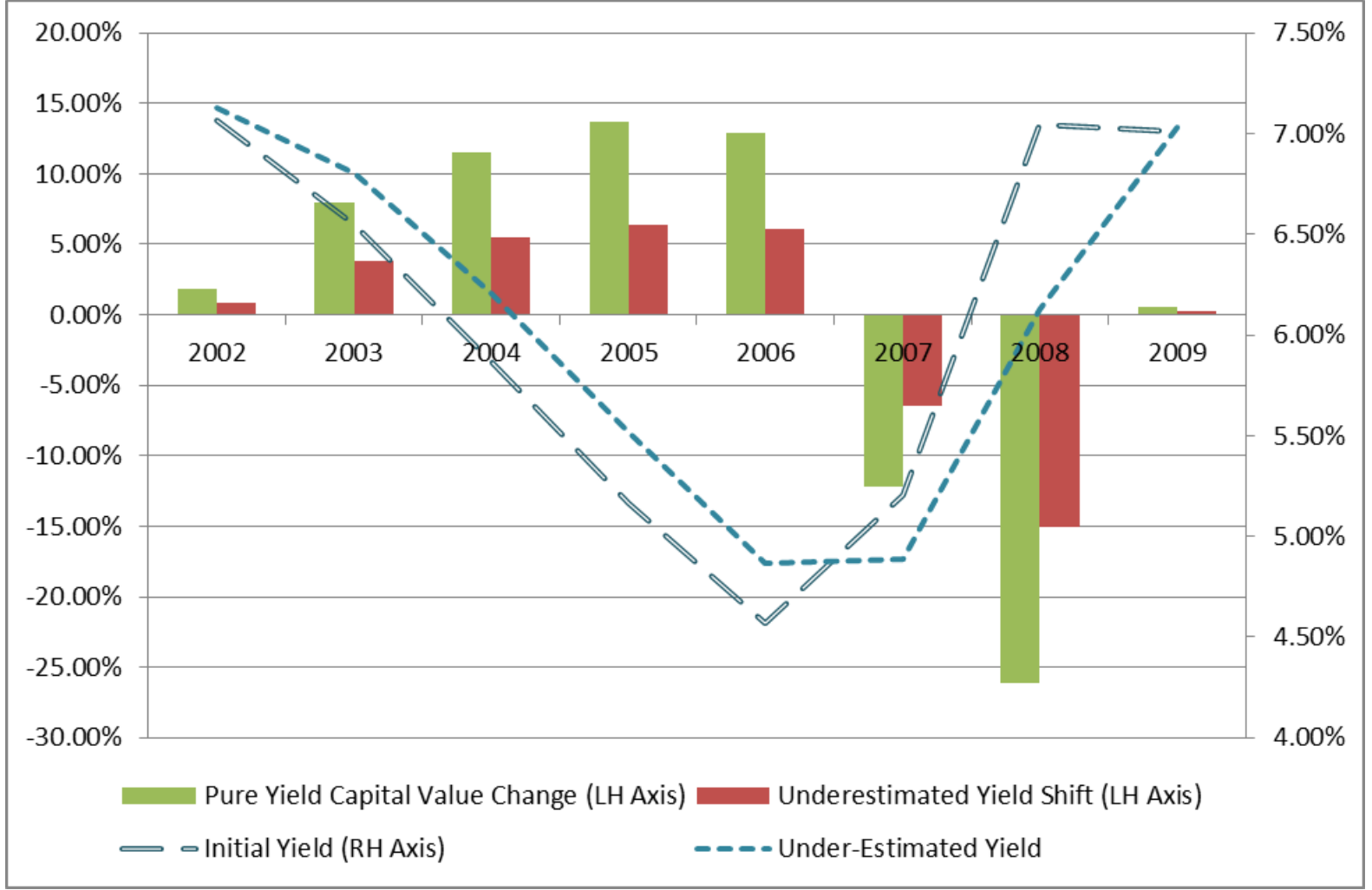

Notes: the adjusted yield is based upon a forecast that captures $50 \%$ of the movement in the yield. 


\section{Endnotes:}

${ }^{1}$ A small number of the papers to have considered forecasts in the equity sector include: Barber et al. (2007); Clarke \& Subramanian (2006); Clarke et al. (2006), Clement et al. (2011); Cooper et al. (2001); Cowen et al. (2006); Dechow et al. (2000); Hong \& Kubik (2003); Jung et al. (2012); Kim et al. (2011); Welch (2000).

${ }^{2}$ A selection of the literature to have empirical considered the accuracy of macroeconomic series includes; Diebold \& Mariano (1995); Ehrbeck \& Waldmann (1996); Granger \& Pesaran (1999); Laster et al., (1999); White (2000); Lamont (2002); Pons-Novell (2003); Ottaviani \& Sorensen (2006); Batchelor (2007); Stekler (2007); Elliot et al. (2008); Lahiri \& Sheng (2008, 2010); Ager et al. (2009); Patton \& Timmermann (2010); Dovern \& Weisser (2011); Tillman (2011); Dovern et al., (2012)

${ }^{3}$ For a general overview on judgemental forecasting see Lawrence et al. (2006).

${ }^{4}$ e.g. Ehrbeck \& Waldmann (1996); Laster et al. (1999); Lamont (2002); Pons-Novell (2003); Ottaviani \& Sorensen (2006); Elliot et al. (2008); Patton \& Timmermann (2010).

${ }^{5}$ There are also a number of papers to have specifically looked at herding across equity analysts', e.g. Welch (2000), Bernhardt et al. (2006) and Mensah \& Yang (2008).

${ }^{6}$ The analysis is limited to the UK commercial real estate market purely due to data availability. The IPF do collect some data for continental markets but it is limited in scope. Likewise, there are no comparable professional forecasts for the residential sector publically available. The only professional forecasts of the residential market that are widely available are those produced by Consensus Economics for housing starts. A recent by Pierdzioch et al. (2012) consider the accuracy of those series for Canada, Japan and the U.S.

${ }^{7}$ The use of appraisal data is the most common approach adopted in the commercial real estate sector. The main exception in this regard is in the United States where NCREIF (National Council of Real Estate Investment Fiduciaries) provide a transaction based index as an alternative to their main appraisal/valuation based benchmarks.

${ }^{8}$ This variability and the low sample size for individual firm types in some periods meant that an analysis across different forecasters was not viable.

${ }^{9}$ Whilst subsequent adjustments to the IPD indices are relatively infrequent and minor, we use the data available at the time of the forecast.

${ }^{10}$ The reverse may also be argued, in the sense that reduced expertise when incorporating nonoccupier market elements into capital values forecasts may contribute to reduced accuracy.

${ }^{11}$ The mid-seventies oil crisis resulted in an increase in interest rates, followed by a corresponding rise in property yields, resulting in a negative yield impact. The 1992/93 period is primarily related to the departure of Sterling from the European Exchange Rate Mechanism (ERM). Following Sterling's departure in September 1992, the Bank of England was able to set UK interest rates solely based upon domestic economic conditions. This was in contrast to the exchange rate policy dominated approach previously adopted in an attempt to maintain Sterling's position within its ERM bands. The result of Sterling's departure was a reduction in UK rates in late 1992 and 1993, with a corresponding downward movement in property yields, thus a large positive yield impact.

${ }^{12}$ See Stevenson et al. (2014) for a broader discussion about the impact of flow of funds on investor behaviour in a real estate context. 
${ }^{13}$ The IPD initial yield series is based upon the simple ratio of current rental income divided by capital value. It does not take into account the lease structures in place and possibly uplifts in income. In many respects it is therefore similar to the dividend yield in that divides current income by the current asset price. 